AperTO - Archivio Istituzionale Open Access dell'Università di Torino

\title{
Activity of the EGFR-HER2 dual inhibitor afatinib in EGFR-mutant lung cancer patients with acquired resistance to reversible EGFR tyrosine kinase inhibitors.
}

\section{This is the author's manuscript}

Original Citation:

\section{Availability:}

This version is available http://hdl.handle.net/2318/150605

since 2016-09-15T12:45:30Z

Published version:

DOI:10.1016/j.cllc.2014.07.002

Terms of use:

Open Access

Anyone can freely access the full text of works made available as "Open Access". Works made available under a Creative Commons license can be used according to the terms and conditions of said license. Use of all other works requires consent of the right holder (author or publisher) if not exempted from copyright protection by the applicable law. 


\section{(2) \\ UNIVERSITÀ DEGLI STUDI DI TORINO}

Questa è la versione dell'autore dell'opera:

Activity of the EGFR-HER2 Dual Inhibitor Afatinib in EGFR-Mutant Lung Cancer Patients With Acquired Resistance to Reversible EGFR Tyrosine Kinase Inhibitors

Landi L, Tiseo M, Chiari R, Ricciardi S, Rossi E, Galetta D, Novello S, Milella M, D'Incecco A, Minuti G, Tibaldi C, Salvini J, Facchinetti F, Haspinger ER, Cortinovis D, Santo A, Banna G, Catino A, GiajLevra M, Crinò L, de Marinis F, Cappuzzo F.

Clin Lung Cancer. 2014 Nov;15(6):411-417.e4. doi: 10.1016/j.cllc.2014.07.002. Epub 2014 Aug 16. La versione definitiva è disponibile alla URL:

http://www.sciencedirect.com/science/article/pii/S1525730414001430 
Landi L, Tiseo M, Chiari R, Ricciardi S, Rossi E, Galetta D, Novello S, Milella M, D'Incecco A, Minuti G, Tibaldi C, Salvini J, Facchinetti F, Haspinger ER, Cortinovis D, Santo A, Banna G, Catino A, GiajLevra M, Crinò L, de Marinis F, Cappuzzo F.

\section{Abstract}

\section{Background}

The purpose of this study was to evaluate the efficacy of afatinib in EGFR-mutant metastatic NSCLC patients with acquired resistance to erlotinib or gefitinib.

\section{Materials and Methods}

We retrospectively analyzed the outcome of patients with EGFR-mutant advanced NSCLC treated with afatinib after failure of chemotherapy and EGFR TKIs.

\section{Results}

A total of 96 individuals were included in the study. According to EGFR status, most patients $(n=63 ; 65.6 \%)$ harbored a deletion in exon 19, and de novo T790M mutation was detected in 2 cases (T790M and exon 19). Twenty-four (25\%) patients underwent repeated biopsy immediately before starting afatinib and secondary T790M was detected in 8 (33\%) samples. Among the 86 patients evaluable for efficacy, response rate was $11.6 \%$, with a median progression free-survival (PFS) and overall survival (OS) of 3.9 and 7.3 months, respectively. No significant difference in PFS and OS was observed according to type of last therapy received before afatinib, type of EGFR mutation or adherence to Jackman criteria, and patients benefiting from afatinib therapy had longer PFS and OS $(P<.001)$. Outcome results for repeated biopsy patients were similar to the whole population, with no evidence of response in T790M-positive patients. All patients were evaluable for toxicity, and $81 \%$ experienced an AE of any grade, with grade 3 to 4 AEs, mainly diarrhea and skin toxicity, occurring in 19 (20\%) patients.

\section{Conclusion}

Our results showed that afatinib has only modest efficacy in a real life population of EGFR mutant NSCLC patients with acquired resistance to erlotinib or gefitinib.

\section{Keywords}

- Acquired resistance;

- Afatinib;

- Erlotinib;

- Gefitinib;

- $\quad \mathrm{NSCLC}$ 


\section{Introduction}

Epidermal growth factor receptor (EGFR)-activating mutations, mainly represented by deletion in exon 19 or the L858R substitution in exon 21, identified a distinct subgroup of non-small-cell lung cancer (NSCLC) with different prognosis and sensitivity to anti-tumor strategies. ${ }^{1,2}$ and 3 Eight large randomized studies have clearly demonstrated the superiority of EGFR tyrosine kinase inhibitors (TKIs) in terms of response rate (RR), progression free-survival (PFS) and tolerability compared with conventional first-line platinum-doublet chemotherapy. 4, 5, 6, 7, 8, 9, 10 and 11 Although no formal advantage in overall survival (OS) has emerged from the aforementioned studies, in all trials median survival was up to 2 to 3 years, indicating that EGFR-TKIs have changed natural history of EGFR-mutated NSCLC. Nevertheless, despite an initial dramatic tumor regression, after a median time of 9 to 12 months, all patients have disease progression due to the occurrence of resistance and the possibility of further control tumor growth inevitably decreases.

From a practical point of view, the widespread use of EGFR-TKIs as first-line therapy translates to an undoubted clinical benefit for EGFR-mutant patients, but it also leads to the emergence of a novel clinical entity. Indeed, EGFRmutant patients with acquired resistance to EGFR TKIs represent a subgroup of individuals for whom approved treatment options are only modestly active and for whom there is an urgent need for novel targeted agents. So far, several mechanisms have been recognized as responsible for acquired resistance, with the secondary T790M mutation-a characteristic point mutation in the exon 20 of the EGFR gene-representing the most prominent, being detectable in more than $50 \%$ of patients exposed to gefitinib or erlotinib. ${ }^{12,13 \text { and } 14}$

Afatinib (Giotrif) is an irreversible HER-family inhibitor and preclinical experience has demonstrated its activity in cell lines harboring EGFR mutations, including the T790M, thus suggesting a potential role in overcoming acquired resistance. ${ }^{15}$ and 16 In 2 trials, the LUX-Lung 1 and LUX-Lung $4,{ }^{17}$ and 18 the role of afatinib was investigated at the daily dose of $50 \mathrm{mg}$ in NSCLC patients resistant to EGFR TKIs defined according to the Jackman criteria, ${ }^{19}$ demonstrating similar results. RR ranged from $8 \%$ to $10 \%$, with a PFS of nearly 4 months, in the whole population and in subgroup analyses. Nevertheless, in both studies there was no molecular restriction for patient selection, thus precluding the possibility to derive definitive conclusions on the role of afatinib in the EGFR-mutant and resistant population.

The aim of the present study was to investigate the efficacy of afatinib in a real-life population of pretreated EGFRmutant NSCLC patients with acquired resistance to reversible EGFR TKIs.

\section{Materials and Methods}

\section{Patient Selection}

In the present study we retrospectively analyzed the outcome of patients with EGFR-mutant advanced NSCLC treated with afatinib after failure of chemotherapy and reversible EGFR TKIs in 11 Italian institutions. Eligibility criteria included: availability of clinical information, such as demographic characteristics, presence of EGFR mutation, toxicity, and efficacy data of afatinib therapy. EGFR mutational status was assessed independently at each institution, according to the Società Italiana di Anatomia Patologica e Citopatologica Diagnostica guidelines and using direct 
sequencing (Sanger method), pyrosequencing, or real-time polymerase chain reaction (Therascreen EGFR29 RGQ PCR

mutation kit, Qiagen, Venlo, Netherlands). ${ }^{20}$ Afatinib was provided by Boehringer Ingelheim Inc as a compassionate use and self-administered at a 50-mg dose orally once daily continuously until disease progression, unacceptable toxicity, or patient refusal to continue. Dose reductions to $40 \mathrm{mg}$ per day and then to $30 \mathrm{mg}$ per day were considered on the basis of individual tolerability. Toxicities were assessed according to the National Cancer Institute Common Terminology Criteria for Adverse Events version 3.0 every 4 weeks. In all patients, tumor assessment was performed every 2 months according to the Response Evaluation Criteria In Solid Tumors (RECIST) criteria ${ }^{21}$ and drug resupply was subordinated to tumor reassessment. Each center received the approval of the local ethics committee for each patient included in the study. All patients provided informed consent.

\section{Statistical Analysis}

A descriptive analysis on baseline characteristics was performed on the cohort of 96 EGFR-mutant lung cancer patients. RR was computed on 86 patients evaluable for efficacy. PFS was calculated from the time of starting therapy with afatinib to date of progression or last radiological assessment, and OS was calculated from the time of starting therapy with afatinib to death or last follow-up, with 95\% confidence intervals using the Kaplan-Meier method. Differences in PFS or OS according to type of EGFR mutations, type of previous therapy, adherence to Jackman criteria, or response to afatinib therapy were evaluated using the Log rank test. The significance level for all analyses was set at $P<.05$. Statistical analysis was performed using SPSS version 20 .

\section{Results}

\section{Patient Characteristics}

A total of 96 consecutive subjects treated with afatinib between 2011 and 2013 were included in the study. Patient demographic and baseline characteristics are listed in Table $1 .{ }^{19}$ Most patients were female $(n=62 ; 64.4 \%)$, never smokers ( $n=62 ; 64.4 \%$ ), with an Eastern Cooperative Oncology Group performance status of 0 to 1 ( $n=89 ; 92.8 \%$ ) and treated with at least 3 or more therapy lines $(n=68 ; 70.8 \%)$. All patients had received previous EGFR TKI treatment such as gefitinib $(n=46 ; 47.9 \%)$, erlotinib $(n=46 ; 47.9 \%)$, or both $(n=4 ; 4.2 \%)$, as their first $(n=27 ; 28.1 \%)$, second $(n=57 ; 59.3 \%)$, or subsequent $(n=19 ; 19.7 \%)$ line of therapy. More than two-thirds of patients $(n=70 ; 72.9 \%)$ responded (complete response $[C R]$ or partial response [PR]) to previous EGFR TKI therapy. Regarding therapy received before starting afatinib, $53.1 \%$ of patients $(n=51)$ received chemotherapy, and $41(41.7 \%)$ fulfilled the Jackman criteria for acquired resistance. Seventeen patients (17.7\%) received 1 or more subsequent lines of therapy after afatinib progression, including gefitinib in 35\%. According to EGFR mutational status, 63 (65.6 \%) patients harbored a mutation in exon 19, 25 (26.0\%) in exon 21, 4 (4.2\%) in exon 18, and 2 (2.1\%) patients had an activating mutation not otherwise specified. De novo T790M mutation was detected in 2 (2.1\%) patients and in both cases it was associated with mutation in exon 19. In 24 patients it was possible to perform a second biopsy immediately before starting afatinib treatment. Secondary T790M was detected in 8 (33\%) samples, in 2 (8\%) samples a novel EGFR mutation in exon 18 was detected, and 2 other (8\%) resulted as wild type, and the remaining 12 (50\%) samples displayed the same EGFR mutation detected at baseline. No additional biomarker was investigated.

Table 1. 


\begin{tabular}{|c|c|c|}
\hline Characteristic & n & $\%$ \\
\hline Median Age (Range) & \multicolumn{2}{|c|}{$62.0(29.6-84.7)$} \\
\hline Men/Women & $34 / 62$ & $35.4 / 64.6$ \\
\hline \multicolumn{3}{|l|}{ Smoking History } \\
\hline Never/former & $62 / 31$ & $64.6 / 32.3$ \\
\hline Current & 3 & 3.1 \\
\hline \multicolumn{3}{|l|}{ ECOG Performance Status } \\
\hline $0 / 1 / 2 / 3$ & $59 / 30 / 6 / 1$ & $61.5 / 31.3 / 6.3 / 1.0$ \\
\hline \multicolumn{3}{|c|}{ Previous Chemotherapy Lines } \\
\hline $1 / 2 / 3 />3$ & $2 / 26 / 34 / 34$ & 2.1/27.1/35.4/35.4 \\
\hline \multicolumn{3}{|c|}{ Best Response to Previous Reversible EGFR-TKI } \\
\hline $\mathrm{CR} / \mathrm{PR} / \mathrm{SD} / \mathrm{PD}$ & $\mid 5 / 65 / 22 / 4$ & || $5.2 / 67.7 / 22.9 / 4.2$ \\
\hline \multicolumn{3}{|l|}{ Previous EGFR-TKI } \\
\hline Gefitinib/erlotinib/both & $43 / 45 / 8$ & $44.8 / 46.9 / 8.3$ \\
\hline \multicolumn{3}{|c|}{ Type of EGFR Mutation at Baseline } \\
\hline Exon 19 & 63 & 65.6 \\
\hline Exon 21 & 25 & 26.0 \\
\hline Exon 20 (T790M) & 2 & 2.1 \\
\hline Exon 18 & 4 & 4.2 \\
\hline Not specified ${ }^{a}$ & 2 & 2.1 \\
\hline \multicolumn{3}{|c|}{ Repeated Biopsy Immediately Before Starting Afatinib } \\
\hline Yes/No & $24 / 72$ & $25 / 75$ \\
\hline
\end{tabular}




\begin{tabular}{|l|l|l||}
\hline Characteristic & n & $\%$ \\
\hline \hline EGFR Status in Repeated Biopsy & 24 & 100 \\
\hline \hline Same mutation of at baseline & 12 & 50.0 \\
\hline \hline EGFR wild type & 2 & 8.3 \\
\hline \hline EGFR mutated + T790M & 8 & 33.4 \\
\hline \hline Other EGFR mutation ${ }^{\text {b }}$ & 2 & 8.3 \\
\hline \hline Last Therapy Before Afatinib & & \\
\hline \hline EGFR-TKI & 45 & 46.9 \\
\hline \hline Chemotherapy & 51 & 53.1 \\
\hline \hline Fulfilled the Jackman Criteria ${ }^{19}$ & & \\
\hline \hline Yes/No & & \\
\hline
\end{tabular}

Abbreviations: $\mathrm{ECOG}=$ Eastern Cooperative Oncology Group; EGFR = epidermal growth factor receptor; TKI = tyrosine kinase inhibitor.

A Unknown means EGFR mutation not otherwise specified.

B Only in exon 18.

\section{Efficacy}

Eighty-six patients were evaluable for response according to RECIST criteria (Table 2). Overall, 10 (11.6\%) patients achieved confirmed response, including 1 CR and 9 PRs, and 38 (44.2\%) obtained disease stabilization (SD) as their best response, with a disease control rate (CR + PR + SD) of 55.8\%; furthermore, an additional 38 (44.2\%) patients' disease progressed within the first 2 months of therapy. All responders had previously responded to reversible EGFRTKIs and for $70 \%$ of them chemotherapy was the last therapy received before afatinib. No difference in RR was detected in patients fulfilling Jackman criteria versus patients not fulfilling the same criteria ( $5 \%$ in both groups).

Table 2.

Response Rate in the Overall Population 


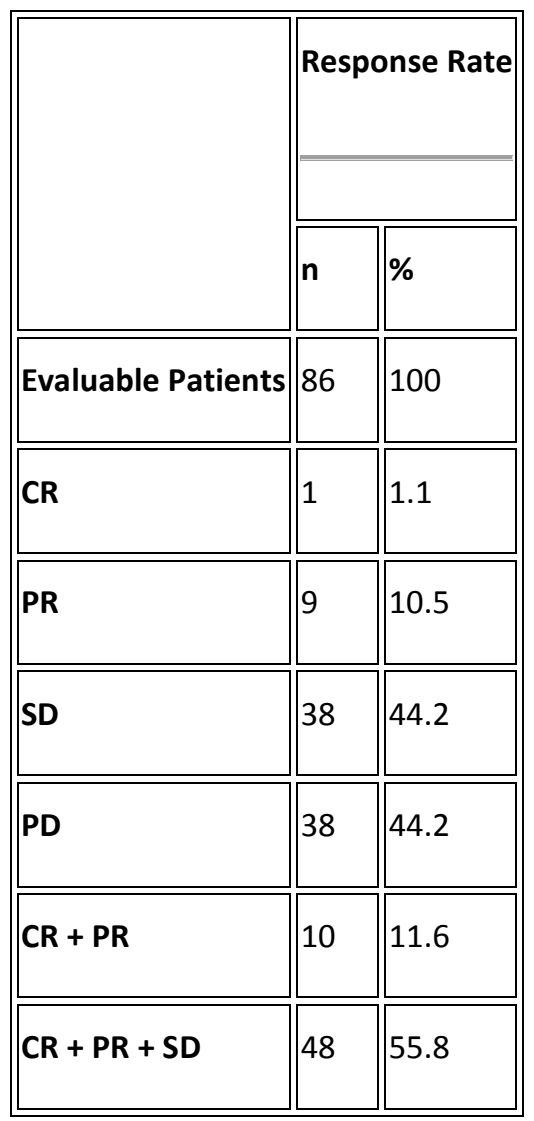

All patients were assessable for PFS and OS. In the whole population, median PFS and OS were 3.9 (95\% confidence interval $[\mathrm{Cl}], 3.26-4.62)$ and $7.3(95 \% \mathrm{Cl}, 4.03-10.69)$ months, respectively (Figure 1). No difference in PFS and OS was observed according to type of last received therapy (EGFR TKIs vs. chemotherapy), type of EGFR mutation (exon 19 vs. exon 21 vs. other) or adherence to Jackman criteria (Supplemental Table 1, Supplemental Figure 1, Supplemental Figure 2 and Supplemental Figure 3). As expected, a significant difference in PFS (7.1 months vs. 1.9 months; $P<.001)$ and OS (13.4 months vs. 4.7 months; $P<.001$ ) was observed for patients benefiting from afatinib therapy ( Figure 2 ).
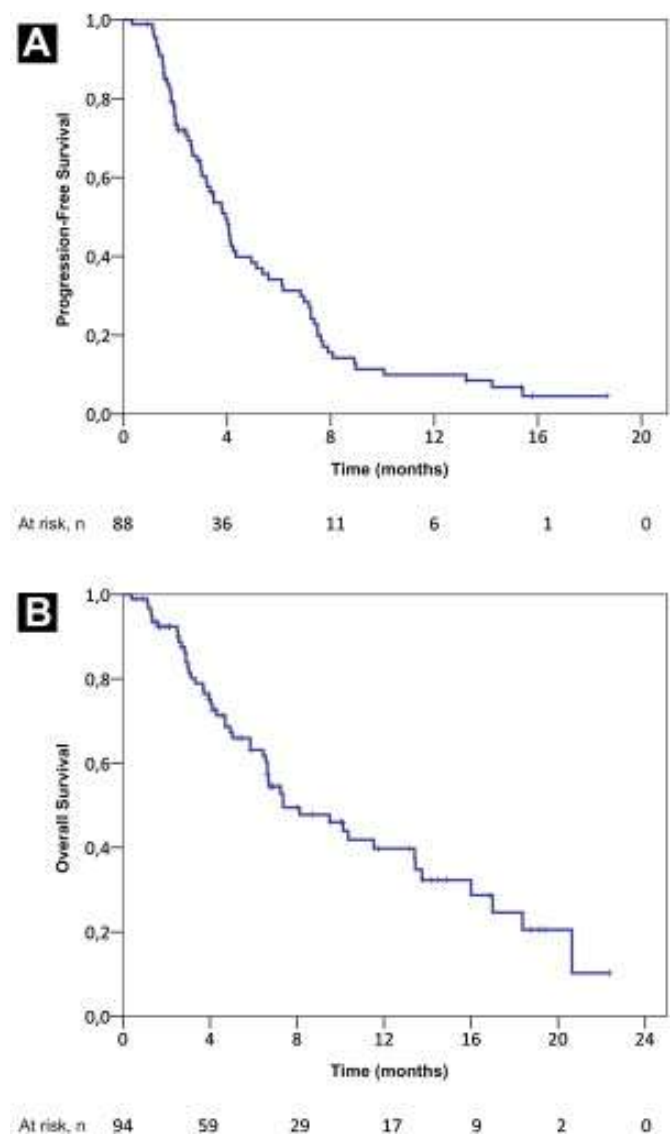
Figure 1.

(A) Kaplan-Meier Curve of Time to Progression-Free Survival and (B) Overall Survival in the Whole Population
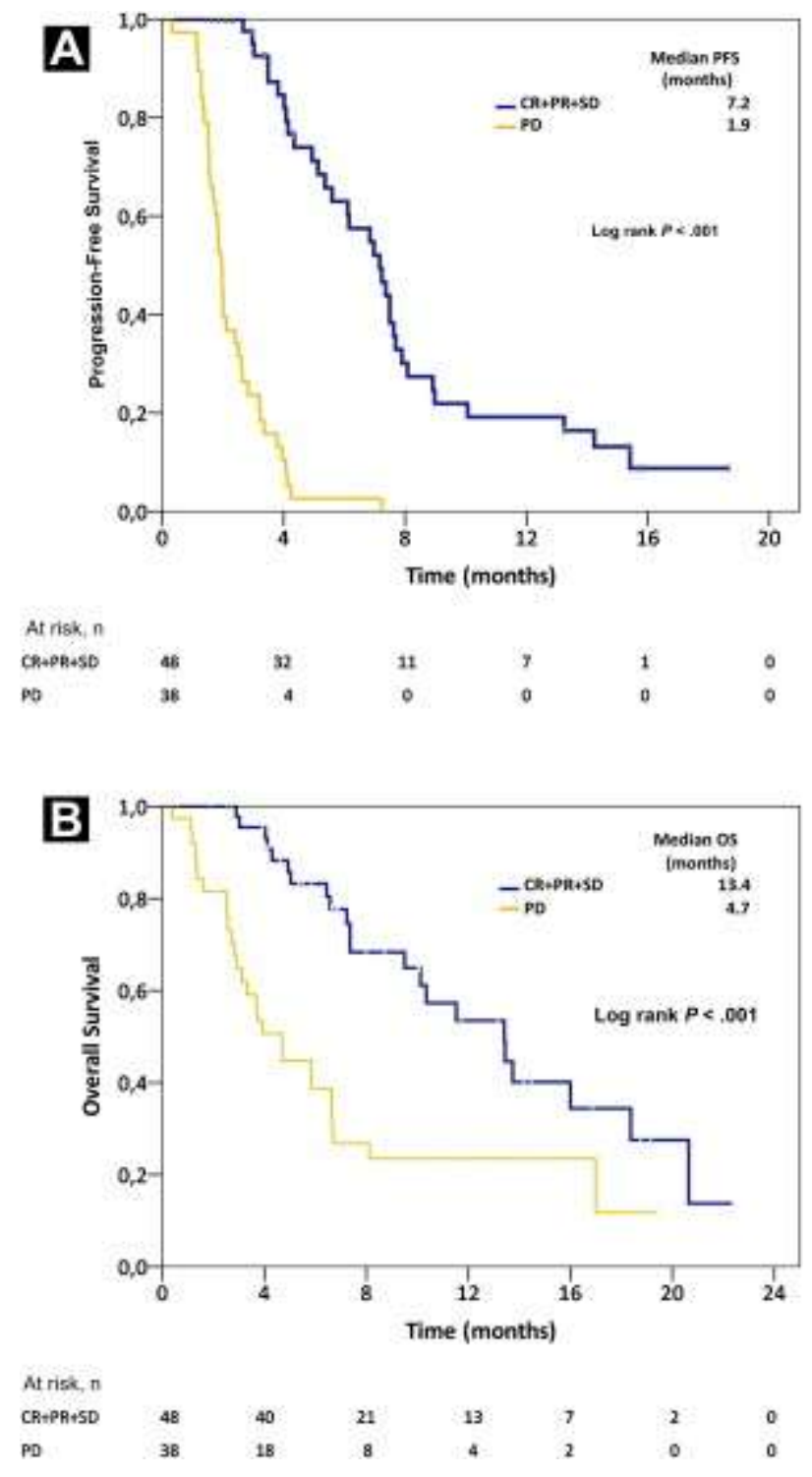

Figure 2.

(A) Kaplan-Meier Curve of Time to Progression-Free Survival and (B) Overall Survival According to Response to Afatinib

Abbreviations: OS = Overall Survival; PFS = Progression-Free Survival.

We further analyzed outcome in the subgroup of patients who received a repeated biopsy. This subgroup was representative of the whole population, with no difference in PFS (3.8 vs. 3.9 months; $P=.5$ ) or OS (10.3 vs. 7.3 months; $P=.2$ ), as shown in Table 3. Among the 22 evaluable patients who receive a repeated biopsy, overall RR was 4.5\% (1 patient with PR), with SD of $45.4 \%$ and a progressive disease (PD) rate of $50 \%$. Notably, none of the 6 individuals harboring the T790M mutation responded, and the only responder had the less common mutation in exon 18 in both tumor samples. 
Table 3.

Outcome in Patients With Repeated Biopsy

\begin{tabular}{|c|c|c|c|c|c|}
\hline Pt ID & $\mid \begin{array}{ll}\text { EGFR } & \text { Status At } \\
\text { Baseline } & \end{array}$ & 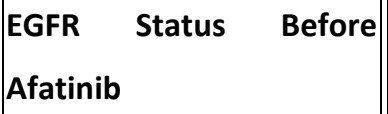 & $\mid \begin{array}{ll}\text { Best } & \text { Response to } \\
\text { Afatinib } & \end{array}$ & $\begin{array}{l}\text { PFS, } \\
\text { Months }\end{array}$ & $\begin{array}{l}\text { OS, } \\
\text { Months }\end{array}$ \\
\hline 2 & Exon 19 & Exon 19 & PD & 2.00 & 14.85 \\
\hline 3 & Exon 19 & Exon $19+\mathrm{T} 790 \mathrm{M}$ & PD & 1.54 & 16.99 \\
\hline 4 & Exon 19 & Exon $19+\mathrm{T} 790 \mathrm{M}$ & SD & 15.41 & 19.16 \\
\hline 5 & Exon 21 & EGFR Wild type & SD & 7.49 & 18.76 \\
\hline 9 & Exon 19 & Exon 19 & SD & 3.48 & 6.44 \\
\hline 10 & Exon 19 & Exon 19 & PD & 1.68 & 6.67 \\
\hline 11 & Exon 18 & Exon 18 & PR & 7.89 & 13.74 \\
\hline 15 & Exon 19 & Exon $19+\mathrm{T} 790 \mathrm{M}$ & PD & 1.97 & 2.14 \\
\hline 31 & Exon 21 & Exon 21 & PD & 7.23 & 19.39 \\
\hline 35 & Exon 19 & Exon $19+$ T790M & SD & 2.27 & 5.32 \\
\hline 42 & Exon 19 & Exon 19 & SD & 8.97 & 13.14 \\
\hline 43 & Exon 19 & Exon 19 & PD & 1.74 & 6.64 \\
\hline 45 & Exon 19 & Exon 19 & PD & 1.97 & 2.89 \\
\hline 47 & Exon 19 & Exon $19+\mathrm{T} 790 \mathrm{M}$ & SD & 8.08 & 9.50 \\
\hline 50 & Exon 19 & EGFR Wild type & PD & 1.84 & 6.70 \\
\hline 55 & Exon 19 & Exon $19+\mathrm{T} 790 \mathrm{M}$ & SD & 3.81 & 3.91 \\
\hline 67 & Exon 21 & Exon $21+\mathrm{T} 790 \mathrm{M}$ & SD & 5.13 & 10.35 \\
\hline 70 & Exon 19 & Exon $19+\mathrm{T} 790 \mathrm{M}$ & PD & 1.18 & 2.50 \\
\hline 73 & Exon 19 & Exon 18 & SD & 1.61 & 1.91 \\
\hline 79 & Exon 19 & Exon 19 & PD & 3.78 & 3.94 \\
\hline
\end{tabular}




\begin{tabular}{|c|c|c|c|c|c|c|c|}
\hline Pt ID & \begin{tabular}{||ll} 
EGFR & Status \\
Baseline &
\end{tabular} & & \begin{tabular}{|ll} 
EGFR & Status \\
Afatinib &
\end{tabular} & Before & $\begin{array}{ll}\text { Best Response to } \\
\text { Afatinib }\end{array}$ & $\begin{array}{l}\text { PFS, } \\
\text { Months }\end{array}$ & $\begin{array}{l}\text { OS, } \\
\text { Months }\end{array}$ \\
\hline 80 & Exon 19 & & Exon 19 & & PD & 1.28 & $\mid 1.31$ \\
\hline 83 & Exon 19 & & Exon 18 & & SD & 4.07 & 14.16 \\
\hline Overall & & & & & RR, 4.5\% & PFS, 3.8 & OS, 10.3 \\
\hline
\end{tabular}

Abbreviations: $E G F R=$ epidermal growth factor receptor; OS = overall survival; PFS = progression-free survival; $R R=$ response rate.

\section{Toxicity}

Ninety-five patients were assessable for toxicity and 77 (81.0\%) subjects experienced a drug-related adverse event $(\mathrm{AE})$ of any grade, including diarrhea and skin toxicity, this latter defined as skin rash/acneiform dermatitis, palmarplantar erythrodysesthesia syndrome, pruritus, xerosis, nail changes, and paronychia (Table 4). Grade 3 to 4 AEs occurred in 19 patients (20\%), with diarrhea and skin toxicity as the most frequent events (10.6\% and $11.6 \%$, respectively); however, the occurrence of both types of adverse reactions was 5\%. Other Grade 3 to 4 AEs included stomatitis in 1 patient and respiratory distress without clinical features of interstitial lung disease in another patient. Overall, 29 patients (30\%) required a dose reduction to $40 \mathrm{mg}(22 \%)$ and to $30 \mathrm{mg}(8 \%)$ because of persistent Grade 2 or 3 skin rash $(24 \%)$, diarrhea (31\%), or both (41\%). Thirty patients (31.6\%) had treatment delays because of toxicity, with only $3.2 \%$ of patients discontinuing afatinib because of unresolved AEs.

Table 4.

Most Common Treatment-Related AEs

\begin{tabular}{|c|c|c|c|c|}
\hline \multirow{2}{*}{ Toxicity } & \multicolumn{2}{|c|}{ All Grade } & \multicolumn{2}{|c|}{ Grade 3/4 } \\
\hline & n & $\%$ & n & $\%$ \\
\hline Evaluable Patients & 95 & 100 & 95 & 100 \\
\hline Total With Any Grade AEs & 77 & 81.0 & 19 & 20.0 \\
\hline Diarrhea & 47 & 49.5 & 10 & 10.6 \\
\hline Cutaneous Toxicity ${ }^{a}$ & 52 & 59.7 & 11 & 11.6 \\
\hline Stomatitis & 1 & 1.0 & 1 & 1.0 \\
\hline
\end{tabular}




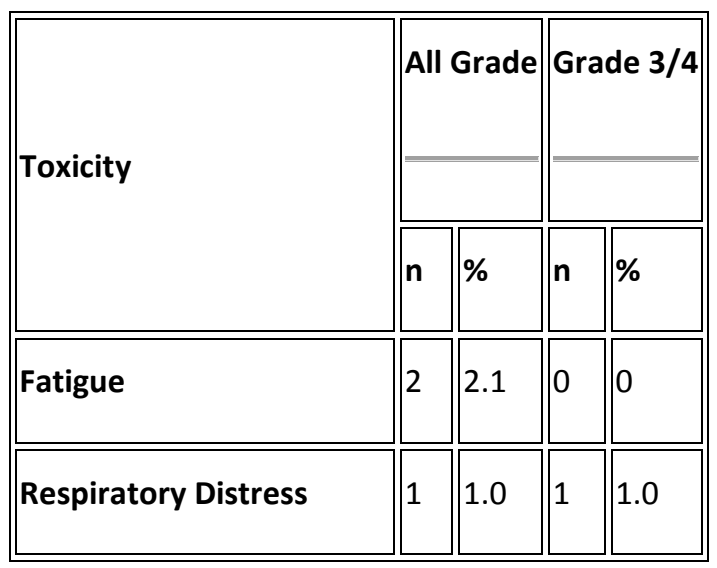

Abbreviation: $\mathrm{AEs}=$ adverse events.

a Cutaneous toxicity included: skin rash/acneiform dermatitis, palmar-plantar erythrodysesthesia syndrome, pruritus, xerosis, nail changes, and paronychia.

\section{Discussion}

The present study, specifically conducted in EGFR-mutated NSCLCs with acquired resistance to erlotinib or gefitinib, showed that afatinib is effective only in a small fraction of NSCLC patients pretreated with reversible EGFR-TKIs.

Epidermal growth factor receptor-mutant NSCLC represents a growing clinical entity for which efficacious therapeutic options are still lacking. In clinical practice, rechallenge with EGFR TKIs has been considered as a reasonable choice and clinical trials are currently under way to investigate such a strategy. In addition, several studies to evaluate retreatment with reversible EGFR-TKIs $22,23,24,25,26,27,28,29,30,31,32$ and 33 or investigate the efficacy of irreversible EGFR TKIs ${ }^{17 \text { and } 18}$ in the setting of acquired resistance to reversible inhibitors showed that there is a constant proportion of patients ranging up to $10 \%$ who continued to benefit from such an agent. $17,18,22,23,24,25,26,27,28,29,30,31,32$ and 33 Nevertheless, it is not possible to accurately predict which patients will further belong to this small subgroup.


interestingly, we noted that in most cases, chemotherapy was the last therapy received before afatinib. Moreover, responding patients progressed later and lived longer than those who did not. Although this result seems too obvious, it reinforce the conviction that irrespective of mechanism responsible for erlotinib or gefitinib failure, reexposure to EGFR-TKIs after a break period could restore the sensitivity to driver inhibition probably because of the reexpansion of the initially sensitive clones. However, for the remaining $90 \%$ of our population, afatinib did not seem to produce any benefit, even when splitting results according to type of EGFR mutation or adherence to Jackman criteria.

From a biological point of view, acquired resistance is a more complex phenomenon than a simple radiologic progression during treatment and a molecular definition should be mandatory, to allocate the correct patient to the correct treatment. Prolonged exposure to erlotinib or gefitinib provides selective pressure for the development of tumor clones able to grow irrespective of the drug inhibition. Some of the mechanisms underlying the phenomenon of secondary resistance are so far elucidated, ${ }^{12,13,14,34,35,36 \text { and } 37}$ including the upregulation of the downstream signal by mesenchymal-epidermal transition amplification, EGFR amplification, phosphatidylinositol-3 kinase catalytic subunit alpha (PI3KCA) mutations, transition from epithelial to mesenchymal differentiation, and for a small percentage of 
resistant tumors, transformation into small-cell lung cancer. Furthermore, several studies recognized the emergence of the T790M EGFR gatekeeper mutation as most prominent, explaining approximately half of gefitinib/erlotinib treatment failures. ${ }^{12,13,14,36 \text { and } 37}$

Because of its ability to arrest tumor growth in in vitro models of EGFR mutant clones resistant to gefitinib and harboring the T790M mutation, afatinib has emerged as the good candidate to test in the clinical setting of acquired resistance with a specific focus on T790M-mediated resistance. ${ }^{15,16 \text { and } 37}$ The combination of afatinib and cetuximab, a monoclonal antibody against EGFR, showed promising efficacy in patients with acquired resistance to EGFR TKIs with an increased risk of toxicity. ${ }^{38}$ Anecdotal series reported a potential efficacy of afatinib even in the presence of the T790M mutation. ${ }^{39 \text { and } 40}$ Nevertheless, additional studies showed the lack of efficacy of the drug in patients with EGFR TKI acquired resistance. ${ }^{17 \text { and } 18}$ The LUX-Lung 1 was a large phase III trial specifically designed to demonstrate the superiority of afatinib versus best supportive care in heavily pretreated NSCLC patients with secondary resistance to reversible EGFR TKIs. Although the study failed to meet its primary end point of OS, a modest but significant improvement in RR and PFS was observed for patients allocated in the active arm than in the placebo arm. ${ }^{17}$ Similarly, in the LUX-Lung 4, a phase II single-arm Japanese trial, RR and PFS were $8.2 \%$ and 4.4 months, respectively. ${ }^{18}$ Notably, in both trials there was not a molecular restriction for patient selection, even if the requirement for at least 12 weeks of previous EGFR TKI treatment was adopted as an enrichment strategy to increase the number of EGFR-mutated patients. As a consequence, archival tissues for EGFR assessment was available in a small percentage of patients, with only 6 cases (4 and 2 patients, in LUX-Lung 1 and LUX-Lung 4, respectively) carrying the T790M; in addiction, tumor samples were collected at the time of initial diagnosis rather than after erlotinib or gefitinib progression, thus precluding the possibility to postulate any hypothesis on the role of afatinib in presence of such a mutation. ${ }^{17 \text { and } 18}$ Although repeating tumor biopsy is not often feasible in NSCLC, in our cohort, a not negligible number of patients underwent repeated biopsy and we identified secondary T790M in 33\% of cases, with no evidence of tumor response. It is interesting to note that 3 of these patients had a relative longer PFS; nevertheless, in such cases we cannot rule out a potential effect of the drug, even if the presence of T790M could be predictive for an indolent outcome. ${ }^{36}$

These unmet expectations could be probably explained by the afatinib ability to inhibit not only the mutated EGFR but also the wild type protein, limiting the use of the optimal dose. ${ }^{15}$ and 41 Therefore, a new potentially effective strategy consists of the use of a new class of covalent irreversible EGFR inhibitors, sparing the EGFR wild type and effective only against the mutated form, including T790M. CO-1686 and AZD6162 are new third-generation EGFR TKIs and preliminary results of 2 recently presented phase I studies showed promising activity in a resistant setting with the absence of typical class-related AEs. ${ }^{42}$ and 43

Taking into account all of these data suggested that the resistant setting is not the correct place to use afatinib. Furthermore, as shown in 2 recently published phase III trials conducted in more than 700 patients, the best performance is obtained when afatinib is used early in the course of disease. ${ }^{10}$ and 11 In LUX-Lung 3 , the first trial to use the most fit comparator arm of cisplatin-pemetrexed, patients treated with afatinib had a $42 \%$ relative reduction in risk of progression compared with those who received standard chemotherapy. ${ }^{10}$ Again, treatment with the EGFR TKI was also associated with greater RR and a better toxicity profile than chemotherapy, although Grade 3 diarrhea and skin rash occurred in $14 \%$ and $16 \%$ of cases receiving the experimental drug, respectively. The second trial, the LUXLung 6, in which afatinib was compared with standard doublet of cisplatin-gemcitabine in an Asian population, 
replicated these findings. Treatment with afatinib doubled PFS, tripled RR, and it was responsible for a $35.6 \%$ of Grade 3 to 4 drug-related AEs, mainly diarrhea and skin rash. ${ }^{11}$

At this proposal, it is a general opinion that afatinib is more toxic than the first-generation TKIs, erlotinib and gefitinib. In the metastatic setting, the preservation of quality of life still remains one of the goals of therapy, mainly in second and subsequent lines of treatment. Moreover, regarding safety profile, our findings were consistent with the well known toxicity profile of afatinib. ${ }^{10,11,17 \text { and } 18}$ In our series we reported an overall incidence of any grade AEs of $81 \%$, quite similar to those described in all afatinib trials. ${ }^{10,11,17 \text { and } 18}$ Furthermore, Grade 3 to 4 AEs, mainly diarrhea and skin rash, occurred in $20 \%$ of subjects. This percentage was not unexpected, probably because we used as a starting dose $50 \mathrm{mg}$, instead of the recommended $40 \mathrm{mg}$ dose. ${ }^{10 \text { and } 11}$ Nevertheless, only $3 \%$ of patients discontinued afatinib because of unresolved toxicity, thus suggesting that, with appropriate dose reduction and adequate supportive care, afatinib was manageable also in a cohort of heavily pretreated patients.

\section{Conclusion}

Our results showed that afatinib has only modest efficacy in a real-life population of EGFR-mutant NSCLCS with acquired resistance to erlotinib or gefitinib and its use in EGFR-mutant patients should be reserved for EGFR TKI naive individuals. Third-generation irreversible EGFR TKIs seem to offer important advantages over older compounds, especially in the management of resistant tumors, and confirmatory trials are urgently awaited.

\section{Clinical Practice Points}

-In EGFR-mutant NSCLC patients, 8 randomized studies have clearly demonstrated the superiority of EGFR-TKIs in terms of outcome and tolerability compared with standard first-line platinum-doublet chemotherapy.

- Currently, the approved treatment options in EGFR-mutant patients with acquired resistance to first-generation EGFR TKIs are only modestly active and there is an urgent need for novel targeted agents.

-Afatinib is a second-generation irreversible HER-family inhibitor and preclinical models suggest a potential role in overcoming acquired resistance, including secondary T790M mutation.

- In patients with acquired resistance to EGFR TKIs, no study has been specifically focused on individuals with EGFR mutations, precluding the possibility to derive definitive conclusions on the role of this drug in resistant cases.

- In our study, we retrospectively evaluated the outcome of 96 EGFR mutant NSCLC patients treated with afatinib after failure of chemotherapy and EGFR TKI treatments. Our data showed that afatinib was effective only in a small fraction of NSCLC patients with acquired resistance to EGFR TKIs.

-Afatinib treatment should be reserved only for EGFR-TKI-naive EGFR-mutant NSCLC patients.

\section{Disclosure}

F.C. and L.C. have received honoraria from AstraZeneca e Roche. F.d.M. has received honoraria from AstraZeneca, Roche, and Boehringer Ingelheim. S.N. has received honoraria from AstraZeneca, Roche, and Eli Lilly. The remaining authors have stated that they have no conflicts of interest. 


\section{Acknowledgments}

This work was supported by the Associazione Italiana per la Ricerca sul Cancro (IG 2012-13157), Fondazione Ricerca Traslazionale, and Istituto Toscano Tumori (Project F13/16).

\section{Supplemental Data}
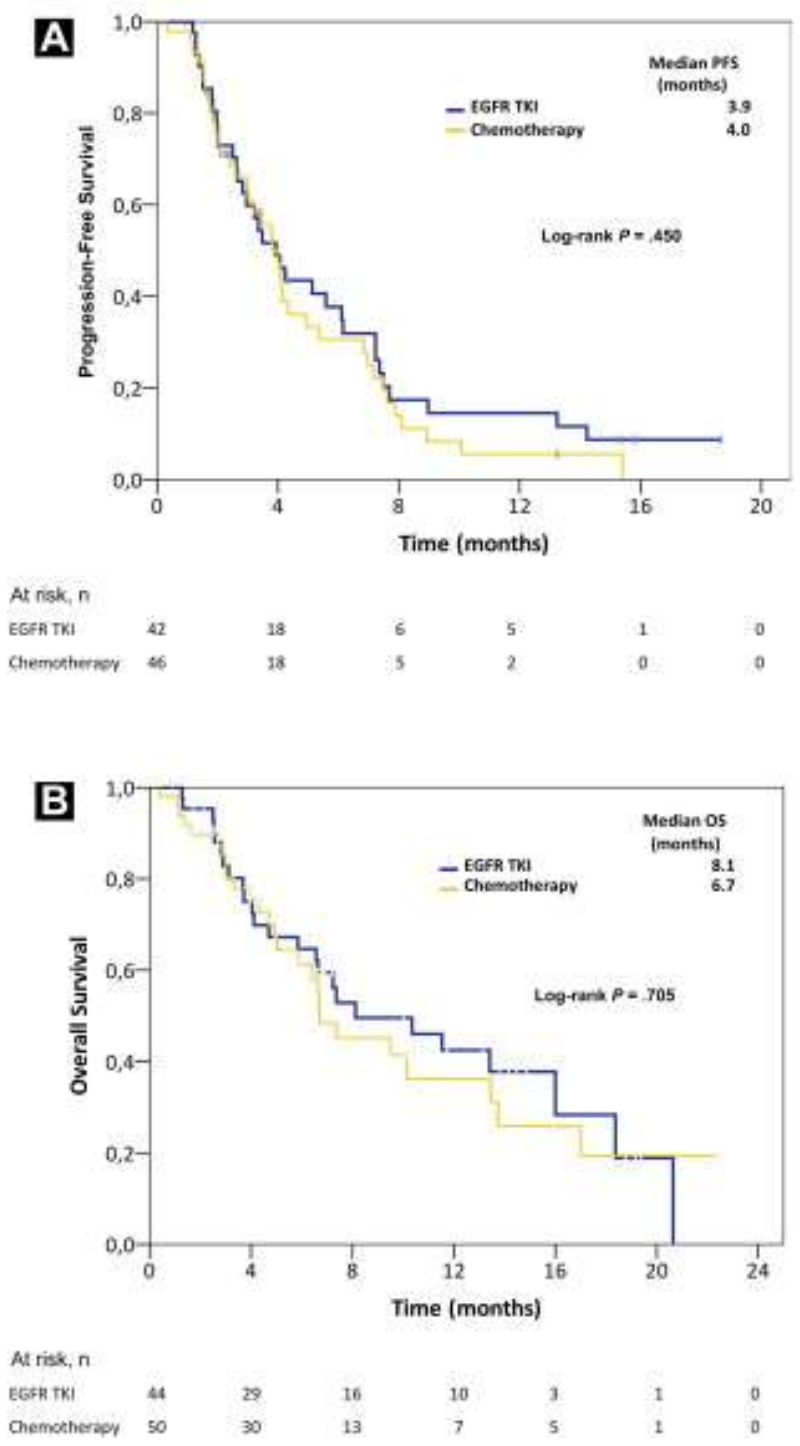

Supplemental Figure 1.

(A) Kaplan-Meier Curve of Time to Progression-Free Survival (PFS) and (B) Overall Survival (OS) According to Therapy Received Before Afatinib

Abbreviations: EGFR = Epidermal Growth Factor Receptor; TKI = Tyrosine Kinase Inhibitor 

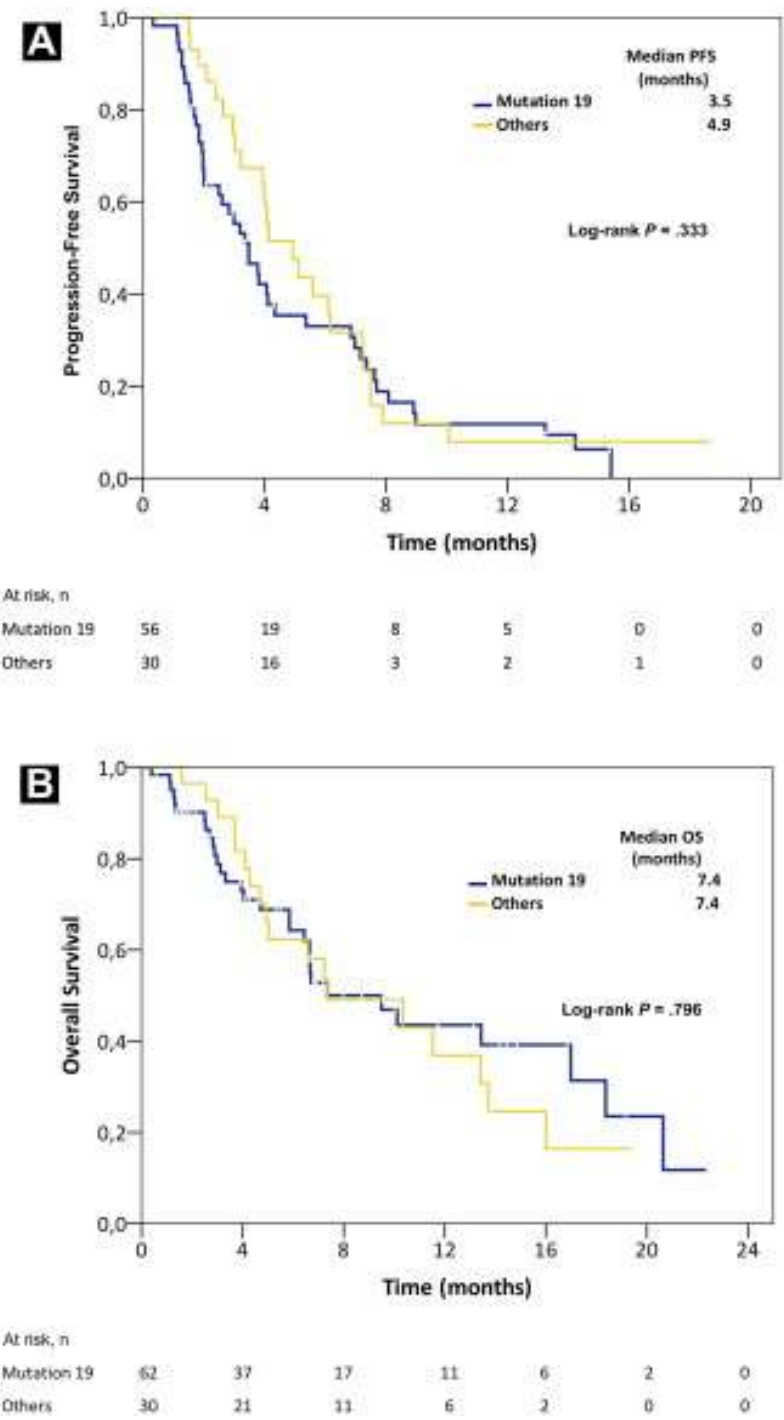

Supplemental Figure 2 .

(A) Kaplan-Meier Curve of Time to Progression-Free Survival (PFS) and (B) Overall Survival (OS) According to Type of EGFR Mutation 



At risk, n

$\begin{array}{llllllll}\text { No } & 54 & 34 & 14 & 8 & 5 & 1 & 0 \\ \text { Yes } & 40 & 25 & 15 & 9 & 3 & 1 & 0\end{array}$

Supplemental Figure 3.

(A) Kaplan-Meier Curve of Time to Progression-Free Survival (PFS) and (B) Overall Survival (OS) According to Jackman Criteria 
Supplemental Table 1.

Outcome Results in Subgroup Analyses

\begin{tabular}{|c|c|c|c|c|c|c|}
\hline & \multicolumn{2}{|c|}{ Last Therapy Before Afatinib } & \multicolumn{2}{|c|}{ Type of Mutation } & \multicolumn{2}{|c|}{ Fulfilled Jackman Criteria } \\
\hline & CT & |EGFR-TKI & Exon 19 & Exon 21 (and Other) & Yes & No \\
\hline Patients, $n$ & |51 & || 45 & 63 & |33 & 40 & ||56 \\
\hline PFS, Months & 4.0 & 3.9 & 3.4 & 4.9 & 3.9 & 3.8 \\
\hline $95 \% \mathrm{Cl}$ & |3.18-4.83 & || $2.75-5.12$ & $2.48-4.47$ & |3.22-6.63 & $2.67-5.20$ & ||2.80-4.81 \\
\hline$P$ & \multicolumn{2}{|l|}{.4} & \multicolumn{2}{|l|}{.3} & \multicolumn{2}{|c|}{.9} \\
\hline OS, Months & 6.7 & 8.1 & 7.3 & 7.3 & 8.1 & 6.7 \\
\hline $95 \% \mathrm{Cl}$ & $3.67-9.72$ & 2.96-13.27 & $3.06-11.66$ & $2.42-12.30$ & $3.32-12.91$ & $3.57-9.83$ \\
\hline$P$ & \multicolumn{2}{|l|}{.7} & \multicolumn{2}{|l|}{.8} & \multicolumn{2}{|l|}{$\mid .6$} \\
\hline
\end{tabular}

Abbreviations: $\mathrm{CT}=$ chemotherapy; $\mathrm{EGFR}=$ epidermal growth factor receptor; $\mathrm{OS}=$ overall survival; $\mathrm{PFS}=$ progressionfree survival; TKI = tyrosine kinase inhibitor. 


\section{References}

1

T.J. Lynch, D.W. Bell, R. Sordella, et al.

Activating mutations in the epidermal growth factor receptor underlying responsiveness of non-small-cell lung cancer to gefitinib

N Engl J Med, 350 (2004), pp. 2129-2139

2

J.G. Paez, P.A. Jänne, J.C. Lee, et al.

EGFR mutations in lung cancer: correlation with clinical response to gefitinib therapy

Science, 304 (2004), pp. 1497-1500

3

C. Gridelli, F. de Marinis, F. Cappuzzo, et al.

Treatment of advanced non-small-cell lung cancer with epidermal growth factor receptor (EGFR) mutation or ALK gene rearrangement: results of an international expert panel meeting of the Italian Association of Thoracic Oncology Clin Lung Cancer, 15 (2014), pp. 173-181

\section{4}

T.S. Mok, Y.L. Wu, S. Thongprasert, et al.

Gefitinib or carboplatin-paclitaxel in pulmonary adenocarcinoma

N Engl J Med, 360 (2009), pp. 947-957

5

J.Y. Han, K. Park, S.W. Kim, et al.

First-SIGNAL: first-line single-agent iressa versus gemcitabine and cisplatin trial in never-smokers with adenocarcinoma of the lung

J Clin Oncol, 30 (2012), pp. 1122-1128

6

T. Mitsudomi, S. Morita, Y. Yatabe, et al.

Gefitinib versus cisplatin plus docetaxel in patients with non-small-cell lung cancer harbouring mutations of the epidermal growth factor receptor (WJTOG3405): an open label, randomised phase 3 trial

Lancet Oncol, 11 (2010), pp. 121-128

7

M. Maemondo, A. Inoue, K. Kobayashi, et al.

Gefitinib or chemotherapy for non-small-cell lung cancer with mutated EGFR

N Engl J Med, 362 (2010), pp. 2380-2388

8

C. Zhou, Y.L. Wu, G. Chen, et al.

Erlotinib versus chemotherapy as first-line treatment for patients with advanced EGFR mutation-positive non-smallcell lung cancer (OPTIMAL, CTONG-0802): a multicentre, open-label, randomised, phase 3 study Lancet Oncol, 12 (2011), pp. 735-742

9

R. Rosell, E. Carcereny, R. Gervais, et al. 
Erlotinib versus standard chemotherapy as first-line treatment for European patients with advanced EGFR mutationpositive non-small-cell lung cancer (EURTAC): a multicentre, open-label, randomised phase 3 trial

Lancet Oncol, 13 (2012), pp. 239-246

10

L.V. Sequist, J.C. Yang, N. Yamamoto, et al.

Phase III study of afatinib or cisplatin plus pemetrexed in patients with metastatic lung adenocarcinoma with EGFR mutations

J Clin Oncol, 31 (2012), pp. 3327-3334

11

Y.L. Wu, C. Zhou, C.P. Hu, et al.

Afatinib versus cisplatin plus gemcitabine for first-line treatment of Asian patients with advanced non-small-cell lung cancer harboring EGFR mutations (LUX-Lung 6): an open-label, randomised phase 3 trial

Lancet Oncol, 15 (2014), pp. 213-222

12

L.V. Sequist, A.W. Waltman, D. Dias-Santagata, et al.

Genotyping and histological evolution of lung cancers acquiring resistance to EGFR inhibitors

Sci Transl Med, 3 (2011), p. 75ra26

13

W. Pao, V.A. Miller, K.A. Politi, et al.

Acquired resistance of lung adenocarcinomas to gefitinib or erlotinib is associated with a second mutation in the EGFR kinase domain

PLoS Med, 2 (2005), p. e73

14

M.E. Arcila, G.R. Oxnard, K. Nafa, et al.

Rebiopsy of lung cancer patients with acquired resistance to EGFR inhibitors and enhanced detection of the T790M mutation using a locked nucleic acid-based assay

Clin Cancer Res, 17 (2011), pp. 1169-1180

15

D. Li, L. Ambrogio, T. Shimamura, et al.

BIBW2992, an irreversible EGFR/HER2 inhibitor highly effective in preclinical lung cancer models

Oncogene, 27 (2008), pp. 4702-4711

16

E.L. Kwak, R. Sordella, D.W. Bell, et al. Irreversible inhibitors of the EGF receptor may circumvent acquired resistance to gefitinib Proc Natl Acad Sci U S A, 102 (2005), pp. 7665-7670

17

V.A. Miller, V. Hirsh, J. Cadranel, et al.

Afatinib versus placebo for patients with advanced, metastatic non-small-cell lung cancer after failure of erlotinib, gefitinib, or both, and one or two lines of chemotherapy (LUX- Lung 1): a phase 2b/3 randomised trial Lancet Oncol, 13 (2012), pp. 528-538 
N. Katakami, S. Atagi, K. Goto, et al.

LUX-Lung 4: a phase II trial of afatinib in patients with advanced non-small-cell lung cancer who progressed during prior treatment with erlotinib, gefitinib, or both

J Clin Oncol, 31 (2013), pp. 3335-3341

19

D. Jackman, W. Pao, G.J. Riely, et al.

Clinical definition of acquired resistance to epidermal growth factor receptor tyrosine kinase inhibitors in non-smallcell lung cancer

J Clin Oncol, 28 (2010), pp. 357-360

20

A. Marchetti, N. Normanno, AIOM - SIAPEC-IAP, et al.

Recommendations for mutational analysis of EGFR in lung carcinoma

Pathologica, 102 (2010), pp. 119-126

21

P. Therasse, S.G. Arbuck, E.A. Eisenhauer, et al.

New guidelines to evaluate the response to treatment in solid tumors. European Organization for Research and Treatment of Cancer, National Cancer Institute of the United States, National Cancer Institute of Canada

J Natl Cancer Inst, 92 (2000), pp. 205-216

22

S. Watanabe, J. Tanaka, T. Ota, et al.

Clinical responses to EGFR-tyrosine kinase inhibitor retreatment in non-small-cell lung cancer patients who benefited from prior effective gefitinib therapy: a retrospective analysis

BMC Cancer, 11 (2011), p. 1

23

H. Asahina, S. Oizumi, A. Inoue, et al.

Phase II study of gefitinib readministration in patients with advanced non-small-cell lung cancer and previous response to gefitinib

Oncology, 79 (2010), pp. 423-429

24

I.J. Oh, H.J. Ban, K.S. Kim, et al.

Retreatment of gefitinib in patients with non-small-cell lung cancer who previously controlled to gefitinib: a singlearm, open-label, phase II study

Lung Cancer, 77 (2012), pp. 121-127

25

H. Yokouchi, K. Yamazaki, I. Kinoshita, et al.

Clinical benefit of readministration of gefitinib for initial gefitinib-responders with non-small-cell lung cancer

BMC Cancer, 7 (2007), p. 51

26

A. Becker, L. Crombag, D.A. Heideman, et al.

Retreatment with erlotinib: regain of TKI sensitivity following a drug holiday for patients with NSCLC who initially responded to EGFR-TKI treatment

Eur J Cancer, 47 (2011), pp. 2603-2606 
B.C. Cho, C.K. Im, M.S. Park, et al.

Phase II study of erlotinib in advanced non-small-cell lung cancer after failure of gefitinib

J Clin Oncol, 25 (2007), pp. 2528-2533

28

Z. Song, X. Yu, C. He, et al.

Re-administration after the failure of gefitinib or erlotinib in patients with advanced non-small-cell lung cancer J Thorac Dis, 5 (2013), pp. 400-405

29

Z.T. Zhou, X.H. Xu, Q. Wei, et al.

Erlotinib in advanced non-small-cell lung cancer after gefitinib failure

Cancer Chemother Pharmacol, 64 (2009), pp. 1123-1127

30

A. Hata, N. Katakami, H. Yoshioka, et al.

Erlotinib after gefitinib failure in relapsed non-small-cell lung cancer: clinical benefit with optimal patient selection Lung Cancer, 74 (2011), pp. 268-273

31

D.H. Lee, S.W. Kim, C. Suh, et al.

Phase II study of erlotinib as a salvage treatment for non-small-cell lung cancer patients after failure of gefitinib treatment

Ann Oncol, 19 (2008), pp. 2039-2042

32

D.B. Costa, K.S. Nguyen, B.C. Cho, et al.

Effects of erlotinib in EGFR-mutated non-small-cell lung cancers with resistance to gefitinib

Clin Cancer Res, 14 (2008), pp. 7060-7067

33

A.S. Wong, R. Soong, S.B. Seah, et al.

Evidence for disease control with erlotinib after gefitinib failure in typical gefitinib-sensitive Asian patients with nonsmall-cell lung cancer

J Thorac Oncol, 3 (2008), pp. 400-404

34

J.A. Engelman, K. Zejnullahu, T. Mitsudomi, et al.

MET amplification leads to gefitinib resistance in lung cancer by activating ERBB3 signaling

Science, 316 (2007), pp. 1039-1043

35

J. Bean, C. Brennan, J. Shih, et al.

MET amplification occurs with or without T790M mutations in EGFR mutant lung tumors with acquired resistance to gefitinib or erlotinib

Proc Natl Acad Sci U S A, 104 (2007), pp. 20932-20937

36

G.R. Oxnard, M.E. Arcila, C.S. Sima, et al. 
Acquired resistance to EGFR tyrosine kinase inhibitors in EGFR-mutant lung cancer: distinct natural history of patients with tumors harboring the T790M mutation

Clin Cancer Res, 17 (2011), pp. 1616-1622

37

C.H. Yun, K.E. Mengawasser, A.V. Toms, et al.

The T790M mutation in the EGFR kinase causes drug resistance by increasing the affinity for ATP

Proc Natl Acad Sci U S A, 105 (2008), pp. 2070-2075

38

Y.Y. Janjigian, H.J. Groen, L. Horn, et al.

Activity and tolerability of afatinib (BIBW2992) and cetuximab in NSCLC patients with acquired resistance to erlotinib or gefitinib (abstract)

J Clin Oncol, 29 (2011) 482s (abstract 7525)

39

J.M. Sun, M.J. Ahn, Y.L. Choi, et al.

Clinical implications of T790M mutation in patients with acquired resistance to EGFR tyrosine kinase inhibitors

Lung Cancer, 82 (2013), pp. 294-298

40

P. Bordi, M. Tiseo, B. Bortesi, et al.

Overcoming T790M-acquired resistance to EGFR-TKIs in NSCLC with afatinib: a case report

Tumori, 100 (2014), pp. 20e-23e

41

T.A. Yap, L. Vidal, J. Adam, et al.

Phase I trial of the irreversible EGFR and HER2 kinase inhibitor BIBW 2992 in patients with advanced solid tumors

J Clin Oncol, 28 (2010), pp. 3965-3972

42

L.V. Sequist, J.C. Soria, S. Gadgeel, et al.

First-in human evaluation of CO-1686, an irreversible highly selective tyrosine kinase inhibitor of mutations of EGFR (activating and T790M) (abstract)

J Clin Oncol, 32 (2014) 5s (abstract 8010)

43

P.A. Janne, S.S. Ramalingam, J.C. Yang, et al.

Clinical activity of the mutant-selective EGFR inhibitor AZD9291 in patients (pts) with EGFR inhibitor-resistant nonsmall-cell lung cancer (NSCLC) (abstract)

J Clin Oncol, 32 (2014) 5s (abstract) 